"Chasing Hank Aaron's Home Run Record"

by

Steven P. Bisgaier, Benjamin S. Bradley, Peter D. Harwood and Paul M. Sommers

June, 2002

MIDDLEBURY COLLEGE ECONOMICS DISCUSSION PAPER NO. 02-15

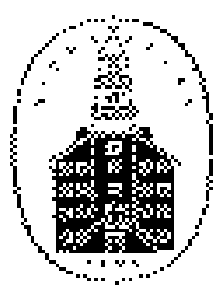

DEPARTMENT OF ECONOMICS

MIDDLEBURY COLLEGE

MIDDLEBURY, VERMONT 05753

http://www.middlebury.edu/ econ 


\title{
Chasing Hank Aaron's Home Run Record
}

by

\author{
Steven P. Bisgaier \\ Benjamin S. Bradley \\ Peter D. Harwood \\ Paul M. Sommers
}

Department of Economics

Middlebury College

Middlebury, Vermont 05753

psommers@panther.middlebury.edu 


\title{
Chasing Hank Aaron's Home Run Record
}

\begin{abstract}
The home run record will last at least long enough to suit me; recently, there was a national contest in which number 715 was voted the most memorable event in baseball history.
\end{abstract}

- Hank Aaron,

I Had A Hammer, 1991 [1]

Slugger Hank Aaron broke Babe Ruth's lifetime home run record of 714 in 1974 and retired two years later with a career total of 755. The alarming frequency with which major leaguers are now knocking balls out of parks has many baseball fans asking not if the home run record will be broken, but when and by whom. The popular choice is either Mark McGwire or Sammy Sosa.

Is Aaron's lifetime home run record within the range of mathematical possibility? The purpose of this brief note is to estimate the probability of four players - Mark McGwire, Sammy Sosa, Ken Griffey Jr., and Alex Rodriguez — eclipsing Aaron's mark by the age of 42 .

The current age and home run statistics of McGwire, Sosa, Griffey, and Rodriguez are shown in Table 1. These data are from the 2000 edition of The Sporting News Baseball Register [2] and www.majorleaguebaseball.com. Averages and standard deviations are based exclusively on all seasons in which the player appeared in more than 100 games, hereafter a "full season".

To break Aaron's lifetime home run record by the time he reaches the age of 42 , Mark McGwire would need an additional 202 (= 756 - 554) home runs over the next five full seasons. Hence, the statistical question becomes: What is the probability that McGwire's five-season average $\bar{x}$ would be at least as large as $40.4(=202 / 5)$ if his career average (to date through the 2000 season) is 45.55 home runs per "full season" with a standard deviation of 14.074? First, we standardize the value $\bar{x}=40.4$ :

$$
z=\frac{\bar{x}-\mu_{0}}{\sigma / \sqrt{n}}=\frac{40.4-45.55}{14.074 / \sqrt{5}}=-0.82
$$


Thus,

$$
\operatorname{Pr}(\bar{x} \geq 40.4)=\operatorname{Pr}(\mathrm{z} \geq-0.82)=.7932
$$

That is, the likelihood of observing an $\bar{x}$ as large or larger than 40.4 when $\mu=45.55$ is .7932. The .7932 is called the $p$-value for the null hypothesis $H_{0}: \mu=45.55$. So long as the $p$-value is greater than 5 percent, then the sample $\bar{x}$ is consistent with the null hypothesis. Loosely speaking, the larger the $p$-value, the stronger the likelihood that the player will break Aaron's career record for home runs.

The $p$-values reported in Table 2 suggest that three players - Mark McGwire, Ken Griffey Jr., and Alex Rodriguez — have better than a 79 percent chance of catching Aaron on the all-time home run list by the age of $42 .{ }^{1}$ McGwire turns 42 in the year 2005

and would (barring injury) be the first to surpass Aaron, ${ }^{2}$ but by these calculations Griffey could be the youngest (at age 40) to reach "756". Similar calculations revealed that power-hitters Jeff Bagwell, Barry Bonds, Jose Canseco, and Mike Piazza probabilistically speaking have virtually no chance (less than two-tenths of one percent) of breaking Aaron's record by their $42^{\text {nd }}$ birthday. Manny Ramirez's chances are slightly better $(p=.2974)$, although still remote.

\section{Concluding Remarks}

Hank Aaron is the all-time, major-league home run leader. His record has stood for over twenty-five years and will likely remain the record for the foreseeable future. Yet, how soon will the name at the top of the home run list change? The calculations presented here suggest that there will not be another all-time home run champion for at least another five years. Several players have a chance at it. First, Mark McGwire and then about four years later Ken Griffey Jr. will pass Aaron, as long as they stay healthy and there are no future strike-shortened seasons. 
Table 1. Home Run Statistics, Selected Players

\begin{tabular}{ccccc} 
Player & Age $^{a}$ & HRs per year & $\begin{array}{c}\text { Standard } \\
\text { deviation }\end{array}$ & $\begin{array}{c}\text { Total HRs } \\
\text { through 2000 }\end{array}$ \\
\hline Mark McGwire & 37 & $45.55(11)$ & 14.074 & 554 \\
Sammy Sosa & 32 & $37.40(10)$ & 17.517 & 386 \\
Ken Griffey Jr. & 31 & $38.27(11)$ & 13.625 & 438 \\
Alex Rodriguez & 25 & $36.80(5)$ & 7.249 & 189 \\
& & & & \\
\hline
\end{tabular}

${ }^{a}$ Age as of April 1, 2001.

${ }^{b} H o m e$ runs per year are based on all seasons in which the player appeared in more than 100 games. The number of such seasons is expressed in parentheses. 
Table 2. Probability of Breaking Hank Aaron's Career Home Run Record, Selected Players

Age at Retirement

$\begin{array}{lllll}38 & 39 & 40 & 41\end{array}$

Player

$\begin{array}{llllll}\text { Mark McGwire } & <.0001 & <.0001 & .0037 & .2407 & .7932\end{array}$

$\begin{array}{llllll}\text { Sammy Sosa } & .0003 & .0098 & .0765 & .2625 & .5288\end{array}$

$\begin{array}{llllll}\text { Ken Griffey, Jr. } & .0823 & .3795 & .7413 & .9335 & .9887\end{array}$

$\begin{array}{llllll}\text { Alex Rodriguez } & .0004 & .0281 & .2966 & .7739 & .9750\end{array}$ 


\section{References}

1. H. Aaron (with Lonnie Wheeler), I Had A Hammer: The Hank Aaron Story, HarperCollins, New York, New York, 1991.

2. The Sporting News Baseball Register, The Sporting News, St. Louis, Missouri, 2000. 


\section{Footnotes}

1. Hank Aaron and Babe Ruth retired at 42 and 40 years of age, respectively. Other all-time leaders on the home run list and their retirement age (as of October 1 in their final season) include: Willie Mays, 42; Frank Robinson, 41; Harmon Killebrew, 39; Reggie Jackson, 41; Mike Schmidt, 40; Mickey Mantle, 36; Jimmie Foxx, 37; and Ted Williams, 42.

3. If Mark McGwire plays until he is 42 , but loses two full seasons to, say, knee injury, the probability that he will surpass Aaron's mark can be read in the " 40 " column of Table 2, namely, only .0037. 